\title{
Práticas de formação continuada em Educação Física ${ }^{1}$
}

Dionésio Anito T. Heringer*

Zenólia Christina Campos Figueiredo**

\begin{abstract}
Resumo: Trata de um estudo em que as práticas de formação são analisadas no momento em que uma professora de Educação Física de uma escola de ensino municipal tenta efetivar as propostas de formação previstas na política sugerida pela Secretaria de Educação. Discorre sobre ocultações que cercam esse campo, geradas por consensos que criam projetos ilusórios. Analisa a escola e a forma como sua organização favorece e/ou dificulta as práticas de formação construídas. Aproxima-se da professora colaboradora para revelar como se organiza esse espaço escolar que se apresenta como determinante na limitação ou constituição dessas práticas de formação.

Palavras-chave: Educação continuada. Educação Física. Prática profissional.
\end{abstract}

\section{INTRODUÇÃo}

Partindo do pensamento comum de que a solução para proble$\operatorname{mas}^{2}$ da educação brasileira é, sobretudo, de responsabilidade dos professores, parte significativa das propostas de mudanças educacionais vem sendo direcionada para a qualificação das intervenções desses profissionais. Associado a essa ideia, o tema qualidade na Educação, sob a ótica da eficiência, ${ }^{3}$ observável em instrumentos

\footnotetext{
1 Este artigo corresponde a uma parte da dissertação de mestrado intitulada "Práticas de Formação Continuada de uma Professora de Educação Física: ocultações, contradições e possibilidades" - Programa de Pós-Graduação em Educação Física, Universidade Federal do Espírito Santo, 2008.

* Mestre em Educação Física pela Universidade Federal do Espírito Santo, Professor Efetivo da Prefeitura Municipal de Vitória. Vitória, ES, Brasil. E-mail: dionesioh@terra.com.br

* Doutora em Educação pela Universidade Federal de Minas Gerais, Professora Adjunto do CEFD/UFES, Coordenadora do Práxis - Centro de Pesquisa de Formação Inicial e Continuada em Educação Física. Belo Horizonte, MG, Brasil. E-mail: zenolia@npd.ufes.br

${ }^{2}$ Resultados insatisfatórios apontados nas avaliações oficiais, fracasso escolar, evasão de alunos, fragilidade na atuação de alguns professores, desvalorização profissional do magistério, descrença na escola pública, etc.

${ }^{3}$ Afirmação mercadológica que implica a obtenção do máximo rendimento e do melhor produto ao menor custo possível (MORGADO, 2005).
} 


\section{Artigor Orifimais Dionésio Heringer e Zenólia Figueiredo}

avaliativos implantados de forma oficial, tem sido um dos principais elementos motivadores das políticas públicas para o setor. É nesse cenário que a formação continuada de professores ocupa um lugar central nas políticas de governo.

Seguindo essa tendência de responsabilização do professor e visando a justificar certa ausência do Estado, chega-se a lançar sobre o professor a culpabilidade pela origem de parte dos problemas. Não raro, a ele é imputada uma condição de questionamento de sua competência profissional. Paradoxalmente, numa primeira aproximação com as contradições a que nos remete esse tema, atribui-se, também, ao professor, possibilidades de solução para essas mesmas questões.

Nos deparamos, então, com um terreno instável, onde a carga de responsabilidade vai da acusação e atribuição de culpa ao reconhecimento da capacidade de solucionar problemas. De qualquer forma, para corrigir distorções ou para promover inovações, centra-se na figura do professor a maior parcela de ações no sentido de transformar a Educação contemporânea. Reforçando a importância desse profissional em todas as esferas do processo educativo, alguns estudiosos chamam a atenção para os riscos dessa forma de perceber as soluções para essas e outras questões não resolvidas.

Nesse contexto, nos dedicamos a analisar as tensões e contradições que cercam a formação continuada no dia-a-dia da prática escolar, procurando direcionar nosso olhar para as possibilidades que podem ser criadas e aquelas que se oferecem no momento em que escola e professores se dedicam a materializar a proposta de formação encaminhada pelos gestores.

Priorizamos o acompanhamento de uma professora de Educação Física do Sistema Municipal de Ensino em sua rotina semanal de atuação, dedicando especial atenção às ações mobilizadas por ela para o trabalho docente. Com foco nos momentos de planejamento e estudos, dedicamo-nos a registrar as manifestações dessa professora no contexto profissional em que está inserida, em relação ao projeto de formação encaminhado pela Secretaria Municipal de Educação (SEME). Destacando as tensões que a relação entre professores e gestores tem evidenciado, buscamos focar nossa análise nas manifes-

Movimento, Porto Alegre, v. 15, n. 04, p. 83-105, outubro/dezembro de 2009. 
tações que a proposta política de formação continuada dessa Secretaria tem desencadeado nesse espaço escolar, bem como nas contradições percebidas no decorrer do dia-a-dia dessa professora. Enfim, nosso foco de estudo foram as práticas de formação continuada construídas por uma professora de Educação Física na sua escola de atuação.

\section{As ESCOLHAS METODOLÓGICAS E OS CAMINHOS PERCORRIDOS}

Priorizamos o acompanhamento de uma professora em um dos turnos de trabalho de uma escola, observando, registrando e analisando o dia-a-dia de seus profissionais, com foco na rotina da professora de Educação Física, em suas vivências nas experiências que remetem à sua formação.

Para chegar ao sujeito e ao seu lugar de atuação, decidimos fazer um primeiro contato aplicando um questionário com perguntas que permitissem uma primeira impressão acerca de suas práticas e noções de formação continuada, além do registro da posição desses professores quanto às vivências experimentadas. A organização do questionário procurou garantir o levantamento dos critérios já definidos contemplando alguns outros de caráter mais organizacional: a) ser professor efetivo da Rede Municipal no mínimo há cinco anos, atuando na mesma escola por pelo menos três anos; b) não se remover dessa escola em 2007; c) atuar integralmente em um turno de trabalho; ${ }^{4}$ d) acreditar na formação continuada, atribuindo-lhe um papel relevante em seu crescimento profissional e frequentar regularmente os encontros de área promovidos pela SEME, ao mesmo tempo em que não limite suas iniciativas de formação a esses encontros organizados/ oferecidos pelo sistema, aproveitando e criando outras possibilidades de estudos; e) vivenciar experiências de formação em sua escola como prática constante e necessária e se ver como sujeito desse processo; f) estar disposto a contribuir com a pesquisa.

Tendo como referência esses critérios, analisamos os 42 questionários respondidos e chegamos a duas professoras. No contato pessoal com ambas, pudemos perceber maior receptividade de uma delas.

${ }^{4}$ Alguns professores são obrigados a dividir sua carga horária de trabalho atuando em outras escolas ou na mesma escola em turnos diferentes.

Movimento, Porto Alegre, v. 15, n. 04, p. 83-105, outubro/dezembro de 2009. 


\section{Artigos Orifinais Dionésio Heringer e Zenólia Figueiredo}

Vencida essa etapa, iniciamos nossa incursão procurando conhecer a escola de atuação da professora colaboradora. Quanto ao espaço físico, a escola Vitória possui ótimas condições para o seu funcionamento, carecendo, segundo relato do grupo de professores, de um auditório e mais uma quadra.

Com essas primeiras impressões da escola, consolidamos nosso trabalho de campo no primeiro semestre do ano de 2007. Para tanto, procuramos nos fazer presente no seu dia-a-dia, levantando todas as informações referentes ao nosso objeto de pesquisa. Dialogando com Macedo (2000) e André (1995), acerca dos caminhos a serem percorridos, optamos por utilizar, nessa fase, os seguintes instrumentos: o diário de campo e as entrevistas com registros gravados, o memorial da professora Carmem, os documentos norteadores das políticas da SEME e o Projeto Político-Pedagógico da escola. Esses documentos foram analisados e compuseram nossa trilha rumo ao entendimento do que oficialmente transita na escola em relação às intenções da SEME.

Entramos na escola mantendo contato com seu corpo técnicoadministrativo (CTA), indagando aos pedagogos sobre a forma de atuação e observando a rotina dos planejamentos dos professores da escola, bem como a organização dos espaços coletivos de formação. Nossa intenção, apesar de ter como foco a professora de Educação Física, foi perceber como se organizam esses espaços coletivos. Com a pedagoga que acompanhava a professora Carmem, conseguimos a cópia do Projeto Político-Pedagógico da escola.

Paralelamente a essa frente de observação e imersão, acompanhamos alguns encontros de diretores e pedagogos para entender a proposta política de formação sugerida pelo órgão central. Solicitamos à Gerência de Formação e Desenvolvimento da Educação o documento norteador das políticas de formação para o ano de 2007, que passou a fazer parte dos documentos a serem analisados. No interior da escola, detivemo-nos em acompanhar a professora Carmem em sua rotina diária de atuação. Observamos algumas aulas, instrumentos de avaliação, cadernos de alunos, o caderno de planejamento da professora e, principalmente, acompanhamos seus planejamentos e momentos de estudos realizados nesse período em que estivemos na escola.

Movimento, Porto Alegre, v. 15, n. 04, p. 83-105, outubro/dezembro de 2009. 
O primeiro passo, nesse sentido, foi a preparação de um cronograma de observações. De posse dos horários de atuação da professora, traçamos esse cronograma, levando em consideração, principalmente, seus momentos de planejamentos. Acompanhando-a, nossa intenção foi entender o movimento que gira em torno da constituição desses planejamentos, desde a participação dos demais professores de Educação Física da escola, passando pelos pedagogos, professores de outras áreas, até sua efetivação. Como estratégia para garantir uma sequência coerente no acompanhamento, centramos nossa observação em uma de suas turmas.

Além do acompanhamento específico dos planejamentos, dedicamos a observar e tentar compreender os movimentos desencadeados por aquele coletivo no tocante à participação, ou não, nas experiências de formação continuada vivenciadas na escola, buscando entender desde o funcionamento dos espaços previstos no cronograma preparado pelo órgão central, pela política da Gerência de Formação e Desenvolvimento da Educação (GFDE/SEME), até aqueles planejados e organizados pela própria escola. Em se tratando desses últimos, nossa intenção foi entender os movimentos que se destacam em sua organização.

Nossa rotina de trabalho de campo constituiu-se numa experiência de aproximação com o dia-a-dia da professora Carmem. Em alguns momentos nos colocamos em um canto da sala, na expectativa de perceber trocas de experiências entre Carmem e a outra professora de Educação Física, bem como entre ela e algum outro professor também em planejamento. Além disso, nossa presença permitiu perceber o envolvimento da pedagoga que acompanha os planejamentos da professora.

Um outro momento importante de observação foram os encontros promovidos em função do cronograma de formação sugerido pela SEME. Nesse ambiente, pudemos observar as reações do coletivo de professores, a política de formação sugerida, bem como a forma de envolvimento e participação da professora Carmem.

Por último, com uma importância singular na constituição de nossa impressão acerca das iniciativas de formação experimentadas 
pelos professores, em especial a de Educação Física, acompanhamos os encontros organizados por seu coletivo.

\section{Os "LUGARES COMUNS" DA FORMAÇÃo CONTINUADA}

No intuito de entender um pouco desse fenômeno em que se transformou a formação de professores, dialogamos com algumas ideias constituídas sobre a formação continuada analisando algumas de suas formas de manifestação, suas variáveis, no tocante aos princípios teóricos em que se sustenta, bem como às diferentes formas de materialização nos contextos educacionais. Como nosso objeto transita principalmente pela Educação Física, nosso olhar deteve-se, de forma particular, numa análise das experiências específicas desse campo.

A necessidade de aprofundar essa noção de formação continuada e de conhecer suas formas de manifestação e as teorias em que se sustentam se deve a uma busca para entender as reações dos professores a cada situação de formação. Pretendíamos identificar os consensos criados nesse campo, suas ocultações e contradições e a forma como os espaços escolares, com seus diferentes e também contraditórios sujeitos, se organizam para atender a essa crescente demanda educacional.

Nesse contexto, quer por movimentos internos da escola, quer por aqueles externos, a demanda por transformações tem pautado boa parte das pesquisas educacionais. Mais recentemente, eclodiu a ideia de qualidade do ensino e da profissionalização docente, acrescentando o debate das necessidades de mudanças e diferentes propostas no sentido de promover uma "eficácia educativa"(CORREIA, 1999).

Com uma influência muito forte dos princípios da racionalidade técnica, as propostas para a formação continuada que perseguiram/ perseguem essa "eficácia" traçaram um longo caminho de experiências registradas nas últimas décadas. Questionamentos gerados a esses princípios conduziram a uma frente de estudos que lançaram um outro olhar conceitual sobre esse campo.

Essas noções de formação continuada refletem as fases evolutivas da educação de forma geral. Se, num primeiro momento, o que

Movimento, Porto Alegre, v. 15, n. 04, p. 83-105, outubro/dezembro de 2009. 
se vivenciou foram experiências em que predominavam os princípios positivistas da racionalidade técnica, geralmente, marcadas por cursos rápidos com objetivos predefinidos e estratégias pensadas para complementar a formação inicial, em que o professor era percebido com a passividade de um bom ouvinte, avançamos sob a influência de uma epistemologia de inspiração fenomenológica e/ou interacionista (ESTRELA, 2006), em que esse mesmo professor passa a ser sujeito do processo de formação, com propostas de reflexão sobre e para além de sua prática.

Um artigo publicado na Revista Brasileira de Ciência do Esporte, maio de 2001 (SHEIBE; BAZZO, 2001) aponta que, desde o final da década de 1970, a questão da necessidade de reformulação dos cursos de formação de educadores vem sendo discutida. O debate se amplia na década seguinte, por ocasião da instalação do Comitê Nacional Pró-Formação do Educador, durante a I Conferência Brasileira de Educadores em São Paulo e, mais tarde, culminando com a criação da Associação Nacional Pela Formação dos Profissionais da Educação (Anfope), ${ }^{5}$ no início dos anos 90. Essa discussão materializa-se na forma de um movimento em favor da docência como fator de identidade profissional.

Buscando entender os princípios que determinam o modo como têm se manifestado as experiências de formação continuada, principalmente no campo da Educação Física, deparamo-nos com as seguintes possibilidades (MOLINA; MOLINA NETO, 2001):

\footnotetext{
a) experiências que se materializam por iniciativa das instâncias formadoras: universidades de forma geral;

b) experiências que se materializam por iniciativa da instância gestora central: Secretarias de Educação e/ou coordenações centrais de redes de ensino;

c) experiências que se materializam por iniciativa da instância gestora local: coletivo de profissionais de cada escola;
}

\footnotetext{
${ }^{5}$ Entidade que vem liderando desde então a construção coletiva da uma base comum nacional para a formação desses profissionais.

Movimento, Porto Alegre, v. 15, n. 04, p. 83-105, outubro/dezembro de 2009.
} 


\section{Artigor Orifimais Dionésio Heringer e Zenólia Figueiredo}

d) experiências que se materializam por iniciativa pessoal: o professor.

Na tentativa de mapear os estudos registrados em publicações da área da Educação Física, vimos que essas possibilidades ou maneiras de "praticar" e construir a formação continuada se manifestam de múltiplas formas, quase sempre imbricadas em seus momentos de organização. Não raro percebemos experiências de iniciativa dos órgãos de gestão central, em que escolas, professores e universidades estavam diretamente implicados na organização e definição da forma como ocorreu o processo. Um destaque importante nesses registros, seguindo a tendência apontada nos princípios elencados pela Anfope, aponta as instâncias de gestão central como aquelas que mais assumem a responsabilidade pela organização de espaços/tempos de formação.

Tentando garantir a adesão e o envolvimento dos professores nessas propostas de formação, políticas são gestadas em meio a discursos de profissionalização e melhoria na condição de trabalho docente que muito pouco ou nada mudam o chamado "artificialismo retórico" (HARGREAVES apud CORREIA, 1999). Questionando essa tendência de mudanças como forma de garantia dessa propagada "eficácia educativa", os professores têm manifestado um sentimento de resistência ${ }^{6}$ contra a forma como tudo isso chega até as escolas e a noção de "melhoria" presente nessas políticas.

Essa movimentação da escola, buscando e gerando mudanças, num cenário de resistência, conduziu as discussões sobre políticas públicas para uma sequência de investimentos na revalorização profissional. Essa tendência não se traduziu em valorização salarial, mas, sim, em ações de formações com o objetivo de garantir as competências necessárias a uma intervenção que promovesse a qualidade desejada. São muitas as contradições percebidas nessas propostas para a for-

\footnotetext{
${ }^{6} \mathrm{~A}$ ideia de resistência de que tratamos apresenta algumas diferenças em relação à realidade portuguesa. No caso brasileiro, o que temos percebido, além da pouca aceitação às propostas de mudanças encaminhadas de forma oficial, é uma indignação com o quadro de baixos salários, com o excessivo número de aulas dadas e, em alguns casos, com as precárias condições de trabalho. Enquanto os gestores produzem políticas que desconsideram suas expectativas, os educadores fomentam uma desvalorização dessas políticas antes mesmo de conhecê-las.
}

Movimento, Porto Alegre, v. 15, n. 04, p. 83-105, outubro/dezembro de 2009. 
mação que podem ser analisadas a partir do lugar em que cada uma delas é gestada.

Assim, por um lado, temos: as escolas, seus profissionais e aqueles que se dedicam a estudá-la. Esses últimos, desafiados por esse movimento em prol da "eficácia educativa", denunciam o fracasso escolar de um número cada vez maior de alunos, especialmente nas escolas públicas. Para alguns, esse baixo desempenho é gerado pelo empobrecimento do capital cultural das famílias, que, no caso do Brasil, motivadas por políticas assistencialistas, transferem para a escola e seus professores a total responsabilidade pela trajetória escolar de seus filhos.

Em outro lado, estão os gestores públicos, sinalizando para uma necessidade de melhoria na qualidade da Educação pautada na necessidade de universalização da oferta de vagas e de uma padronização de resultados a serem alcançados pelas escolas. Essas políticas de gestão se pautam em um modelo de eficiência que tem como parâmetro as demandas do mercado. Do ponto de vista daqueles que entendem a escola como o espaço que deverá "preparar" o aluno para a vida em sociedade, é lugar comum idealizar um modelo de qualidade para a Educação que percebe esse aluno como um "cliente" no interior de uma lógica de mercado que desconsidera a necessidade de aprofundar a eficiência social da Educação na promoção da democracia social (CORREIA, 1999).

O primeiro impacto evidenciado na relação entre os profissionais e os gestores é a variação de expectativas ao se falar em mudanças e transformações. A própria noção de como se deve organizar e funcionar a escola e qual a sua função como instituição sofre influência desses olhares. Do lugar que ocupa o professor, ao falar em melhoria da escola, tende a sugerir o desenvolvimento integral do sujeito aluno. $\mathrm{O}$ gestor, mesmo que em algum momento esboce algum tipo de preocupação, foca suas demandas no desenvolvimento da sociedade em que esse sujeito está inserido. O que, a princípio, poderia significar uma preocupação comum, assume características divergentes no momento em que o sujeito, pensado pelo gestor, ganha contornos de "peça da engrenagem social". Boa parte das políticas elaboradas no sentido de "preparar" o aluno para atuar preocupa-se em adequá-lo

Movimento, Porto Alegre, v. 15, n. 04, p. 83-105, outubro/dezembro de 2009. 


\section{Artigos Orifimais Dionésio Heringer e Zenólia Figueiredo}

para um determinado modelo social. Em contrapartida, uma visão mais preocupada com o aluno como sujeito histórico-social e centro do processo educativo permite-lhe agir nessa sociedade e questioná-la naquilo em que achar necessário.

Essa tensão percebida entre o que apontam as políticas públicas e o que pretendem os profissionais do magistério, inevitavelmente tende a gerar conflitos. Num universo cercado de ocultações, as práticas desencadeadas no dia-a-dia das escolas refletem as crenças, contradições e resistências dos professores ao lidarem com propostas que geralmente se constroem para e não com esses profissionais.

Uma tendência comum no campo dessas ações de formação é a utilização de noções previamente acordadas como verdadeiras, sem uma análise mais criteriosa sobre as condições em que deverão ser aplicadas. Essas noções, muitas vezes constituídas sem uma necessária verificação empírica, determinam ações políticas que convivem com constantes questionamentos. Geralmente motivados por resultados pouco expressivos, facilmente identificados no pouco envolvimento dos professores, essas políticas convivem com movimentos nem sempre percebidos por aqueles responsáveis por sua elaboração.

Esses movimentos da formação se desenvolvem sob a influência de lógicas acionadas, mesmo que de forma inconsciente, na definição dos problemas, na estruturação das práticas ou na avaliação das soluções. Essas lógicas, definidas por Correia (1999) como "lugares comuns", 7 contribuem para a produção e reprodução de uma comunidade ilusória de ocultações e ilusões partilhadas.

Para esse autor, no campo da formação de professores, destacam-se quatro grandes "lugares comuns" cercados por consensos cognitivos. São eles: a) a qualificação dos profissionais da Educação implica a garantia de uma melhor qualidade do ensino; b) a formação continuada, independente de sua maior ou menor eficiência, contribui sempre para a valorização profissional e a melhoria do desempenho dos

\footnotetext{
${ }^{7}$ Para o autor, os lugares comuns não têm apenas o estatuto de banalidade, mas encontra-se conotado com a ideia de comunhão de um lugar, nomeadamente com a ideia de partilha interiorizada de um espaço e de uma lógica que, sendo predominantemente cognitiva, também é um lugar social.
}

Movimento, Porto Alegre, v. 15, n. 04, p. 83-105, outubro/dezembro de 2009. 
indivíduos; c) as ações de formação serão tanto mais eficazes quanto melhor elas responderem às carências dos professores; d) a melhoria da qualidade do ensino é de tal forma importante que é evidente que toda a sociedade se beneficiará dela.

Se esses "lugares comuns" produzem consensos cognitivos que apontam a melhoria das qualificações de cada um dos educadores acarretando necessariamente uma melhoria na qualidade do ensino, ele oculta, em primeira instância, o papel mediador que a organização do trabalho docente exerce na estruturação das práticas dos professores e a ausência de uma maior reflexão em torno das relações entre "modelo de gestão das escolas" e formação profissional continuada dos professores.

Um segundo plano de ocultações, está na aceitação da ideia de que existe uma relação de causalidade linear entre a eficácia da ação educativa e a eficácia da ação desenvolvida pelo professor. Para o autor, essa aceitação apoia-se na naturalização do trabalho docente, inspirada no modelo taylorista da organização do trabalho industrial, que se estrutura exclusivamente em torno de uma racionalidade instrumental que busca a eficiência na utilização dos recursos disponíveis. Ele destaca que, contrariamente a essa lógica, a performance de um sistema é cada vez menos ativa e depende muito mais da qualidade da organização e de interações comunicacionais entre os atores do que da eficiência da ação de cada um, e também sinaliza a necessidade de a formação ser pensada como instância de (des)construção dos coletivos de trabalho. Para ele, não basta ligar a formação ao trabalho, é necessário integrá-la no próprio trabalho para que este possa ser interrogado e problematizado, em suma, transformado (CORREIA, 1999).

Outro consenso cognitivo sustenta a ideia de que a formação continuada, independentemente da sua maior ou menor eficiência, contribui sempre para a valorização e melhoria do desempenho profissional, gerando uma terceira ocultação que contribui para a manutenção da ilusão de que os sistemas de formação são exclusivamente sistemas de produção e distribuição de qualificação, ocultando seu papel de legitimação dos saberes e gerando a invisibilidade social daqueles saberes e relações com o saber que não circulam no interior

Movimento, Porto Alegre, v. 15, n. 04, p. 83-105, outubro/dezembro de 2009. 


\section{Artigos Orifinais Dionésio Heringer e Zenólia Figueiredo}

das formações. Esse movimento desconsidera a legitimidade dos saberes profissionais construídos nas relações entre pares, conferindolhe uma ausência de dignidade epistemológica para serem elevados à condição de saberes legítimos.

O consenso cognitivo que atribui uma determinação prévia das necessidades do indivíduo, lugar comum da necessidade de formação do "destinatário", produz uma dupla ocultação: a ocultação das determinantes sociopedagógicas que interferem no processo de produção e de identificação das necessidades de formação dos indivíduos e as determinantes socioepistemológicas que estruturam os processos de produção e de distribuição dos saberes científicos que, não necessariamente, devem ser resultado de uma aproximação das concepções positivistas de ciência em que a legitimidade dos saberes se pauta em experiências de racionalidade técnica capazes de produzir modelos para a ação. A não observação dessas variáveis, na definição das ações, pode produzir uma ação de formação que oscila entre o atendimento a uma demanda institucional ou a um pedido espontâneo dos formandos, fruto de seu condicionamento social.

Por último, ainda no plano das ocultações, a naturalização da ideia de que toda a sociedade se beneficiará de uma suposta qualificação da Educação vem acompanhada de uma noção de qualidade sem espaço para discussões éticas e com poucas opções políticas. Aqui, o que está em debate é a própria noção de qualidade que esse movimento desencadeou.

\subsection{DAS OCULTAÇÕES Às POSSIBILIDADES DE ANÁLISE}

Nas trilhas das referências utilizadas no campo da Educação Física (MOLINA; MOLINA NETO, 2001), quando cuidamos das responsabilidades pela realização das ações de formação, decidimos organizar a análise, por meio de alguns movimentos de formação praticados pelos sujeitos que vivem a escola investigada.

Esses movimentos remetem a uma lógica similar ao esquema apresentado por Sacristán (2000), para expor a objetivação do currículo no processo de seu desenvolvimento, na ideia de que não são sequenciais e nem previsíveis, conforme se pensa na prescrição tanto do currículo

Movimento, Porto Alegre, v. 15, n. 04, p. 83-105, outubro/dezembro de 2009. 
como também nos documentos de formação continuada. Ao contrário, são movimentos descontínuos, "tensionados" e que, mesmo assim, favorecem possibilidades de formação. Assim, construímos um esquema (quadro 1) para demonstrar como concebemos esses movimentos ou práticas de formação.

Esse esquema foi adaptado e desenhado por nós a partir do debate acadêmico e político construído em torno da formação continuada. A discussão acadêmica aponta a formação continuada como responsabilidade dos gestores e centros de formação e direito dos professores (SHEIBE; BAZZO, 2001), com destaque para a importância da dimensão pessoal na opção por participar ou não desse movimento (MOLINA; MOLINA NETO, 2001), sugerindo a figura do professor como intelectual crítico capaz de compreender e, se necessário, transformar sua prática (GIROUX, 1997), como uma das possibilidades a serem alcançadas.

Nesse artigo optamos por apresentar parte do esquema com foco na discussão/análise das práticas de formação materializadas pela professora.

\subsubsection{PrÁticAs de FORMAÇÃo MATERIALIZADAS PELA PROFESSORA COLABORADORA}

Se as ações iniciais indicadas pelas instâncias gestoras e por estudos acadêmicos têm a intenção de motivar ações coletivas, as práticas de formação materializadas pela professora Carmem destacam a dimensão individual desse campo. O modelo hegemônico que determina a forma de organização e funcionamento das unidades escolares, aglutinando professores e alunos em uma proposta de atuação partilhada, é o mesmo que impõe o paradoxo da não facilitação de momentos de articulação desse coletivo, restando a cada profissional uma frágil autonomia para definir e conduzir seu próprio processo de formação.

Como vimos em Correia (1999), esse olhar predefinido imposto por consensos cognitivos que, de antemão, determina o que pode e deve compor os processos de formação, tende a ocultar dificuldades e possibilidades que poderiam compor um quadro mais real para as práticas de formação.

Movimento, Porto Alegre, v. 15, n. 04, p. 83-105, outubro/dezembro de 2009. 


\section{Artigos Orifimais Dionésio Heringer e Zenólia Figueiredo}

Em se tratando de ações individuais, essa realidade não é diferente. Constituir processos de formação, sem uma leitura consistente dessas dificuldades e possibilidades, pode contribuir para uma ineficiência dessas práticas, com o "incômodo" de não poder responsabilizar ninguém além de si mesmo. Esse momento individual, se utilizado em consonância com a proposta reflexiva que sugere uma imersão na própria prática, pode desvelar consensos ilusórios, geralmente submersos em certezas construídas por saberes historicamente constituídos pelo sujeito.

$\mathrm{Na}$ tentativa de compreender esses consensos ilusórios e as ocultações que envolvem as práticas individuais, buscamos uma maior aproximação com a professora Carmem. Percebemos nela uma presença envolvente no dia-a-dia da escola, assumindo uma posição de referência em seu contexto geral. Sua prática pode ser apontada como de extremo compromisso profissional. Corroboram para essa constatação fatos como sua participação no Conselho de Escola, seus posicionamentos consistentes em defesa dos interesses de alunos, pais e professores, o respeito e carinho percebidos em seu relacionamento com os sujeitos que frequentam aquele espaço e, principalmente, a seriedade profissional com que participa da vida escolar, de modo geral.

Talvez por ter concluído sua formação inicial em uma realidade curricular predominantemente técnica, sua prática reflete um perfil de grande domínio sobre os conteúdos tradicionais da Educação Física, o que nos aproxima de uma primeira e importante ocultação: mesmo reconhecendo a hegemonia do conteúdo esporte em sua prática pedagógica, Carmem não aparenta assumir, na amplitude necessária, ${ }^{8} \mathrm{a}$ possibilidade de uma formação pessoal no sentido de buscar alternativas de mudanças.

Nesse contexto, nossa presença, observando e registrando sua prática diária, questionando seu nível de consciência sobre a hegemonia desse conteúdo tradicional em sua prática pedagógica, constituiu-se em um interessante espaço de formação. Em dado momento, Carmem

${ }^{8}$ Percebemos uma intenção ainda tímida, nesse sentido.

Movimento, Porto Alegre, v. 15, n. 04, p. 83-105, outubro/dezembro de 2009. 
reconhece sua relação muito forte com o esporte, afirmando ter dificuldades em desenvolver outros conteúdos. Mesmo assim, tem tentado algumas experiências com o frescobol e a capoeira. Apresenta uma prática de organização desse trabalho que desenvolve nas aulas:

Meu registro é bastante simples, como você viu. Faço o que vou trabalhar na semana. Tenho um caderninho, ele está até meio desatualizado. Porque, às vezes, eu não tenho tempo de sentar para estar escrevendo. Escrevo uma folha e depois passo a limpo. Por exemplo: eu já idealizei o que vai ser essa semana para as turmas, mas ainda não tive tempo de sentar para registrar. Até comentei com você o negócio da $8^{\mathrm{a}}$ série. Os planejamentos são semanais e às vezes até quinzenais, eu tenho a segunda-feira e a quinta-feira, no último horário. Às vezes os meninos não vêm para fazer o treinamento, são 50 minutos só e, eu uso para fazer planejamento. Para procurar alguma coisa, para tentar ver alguma coisa, esse espaço é a segunda-feira (CARMEM ENTREVISTA, 2007)

Como podemos observar, apesar de algumas dificuldades, essa professora tem como prática planejar suas aulas. Mesmo que, a princípio, possa parecer um registro de pouca profundidade e, talvez, até mesmo incompleto, percebemos que eram suficientes para the dar segurança naquilo que desenvolvia em cada aula. Por mais de uma vez, quando o assunto da aula solicitava algum tipo de pesquisa, a professora recorreu ao espaço de planejamento para, em livros ou na internet, montar o material para suas aulas. ${ }^{9}$ Numa análise preliminar, o tempo destinado ao planejamento, usado com seriedade pela professora não parece ser suficiente para oferecer momentos de estudos, no sentido de oferecer respostas às questões pessoais levantadas anteriormente.

De modo geral, ela se sente só no planejamento, reclama da ausência da pedagoga atribuindo esse fato à rotina diária da escola, onde se criam demandas estranhas às responsabilidades centrais dessa profissional.

${ }^{9}$ Vale a pena relatar que a escola conta com um computador, na sala de pedagogos, com acesso disponível à internet.

Movimento, Porto Alegre, v. 15, n. 04, p. 83-105, outubro/dezembro de 2009. 


\section{Astigos Originais}

Eu acho que, se a gente não consegue planejar, a gente se perde. Isso é um fato. Eu tenho uma dificuldade grande aqui na escola de estar sentando com os pedagogos para estar fazendo este planejamento. Não porque eles não estão disponíveis para mim. Eles não estão disponíveis, porque têm de assumir sala de aula. Hoje, não sei por que cargas d'água [risos] a Roberta está presente no meu PL, sentou com a gente logo no início, antes de você chegar. Mas isso não é comum, porque, quando ela não está numa sala de $1^{\mathrm{a}}$ a $4^{\mathrm{a}}$ série, ela provavelmente está numa de $5^{\mathrm{a}}$ a $8^{\mathrm{a}}$, cobrindo alguém. Por exemplo: o professor Leandro, de matemática, está à disposição da Justiça e toda terça-feira ele não vêm à escola. Aí, quem assume as aulas dele? A pedagoga. Aí, ficam a professora de Geografia e História sem ela aqui na sala, sentando para o planejamento. (CARMEM - ENTREVISTA, 2007).

De forma bastante enfática, Carmem expressa seu desejo de planejar junto com a pedagoga. Em mais de uma vez, afirma que as demandas da escola inviabilizam essa possibilidade, porém, em dado momento, recorre a recordações de sucesso com outros profissionais dessa área, com quem trabalhou nessa mesma escola, deixando claro que há também uma parcela de responsabilidade da pedagoga nesse quadro. De qualquer forma, as deficiências na organização da escola, no sentido de resolver essas demandas sem inviabilizar o trabalho da pedagoga, são apontadas por ela como um fator decisivo nessa questão.

Para além de representar prejuízos nos planejamentos e articulações pedagógicas, essa fragilidade relatada na organização escolar produz importantes limitações na qualificação das ações de intervenção. Por mais de uma vez, observamos o quanto a falta de articulação contribui para limitar as atuações, tanto individuais quanto coletivas.

Uma importante limitação, que merece registro, deu-se quando da mudança de uma das datas previstas para formação, definida e organizada pela unidade escolar. Na oportunidade, a data prevista foi alterada sem uma consulta prévia aos professores, separando-se, como nova data, um dia em que haveria formação, organizada pela SEME, para a área de Educação Física. Carmem, sentindo-se extre- 
mamente prejudicada, optou por acompanhar a formação já agendada com a SEME.

Em um outro momento, percebemos alguns professores articulando propostas, a serem encaminhadas à SEME, em relação ao grande número de alunos ainda não alfabetizados, identificados na avaliação diagnóstica. Sem a participação da área de Educação Física, Carmem mostrou-se bastante indignada com a forma como se deu o movimento, sem que todos os professores fossem envolvidos.

Ao observarmos essas limitações, pudemos constatar o quanto seria difícil que a proposta política de formação viesse a ser efetivada dentro dessa frágil estrutura de articulação pedagógica, sem um planejamento que contemplasse todas essas dificuldades.

A essa altura da análise, ficou clara a ocultação do principal elemento teórico da proposta de formação, previsto na política de formação encaminhada pela SEME. No momento em que Carmem reconhece um desconhecimento das possibilidades de trabalho com a pesquisa-ação (proposta indicada no documento oficial da SEME), sem um acompanhamento qualificado da pedagoga, que, em tese, deveria ser a profissional da escola capaz de fazer a articulação entre o que aponta a política de formação e as necessidades dos professores e, sem um planejamento inicial que contemplasse uma aproximação teórica com esse tema, não percebemos nenhuma tentativa de efetivação desse movimento de formação em que a pesquisa-ação se apresentava como o eixo central.

Demonstrando uma relativa autonomia, no tocante à proposta da SEME, a experiência dos planejamentos coletivos, envolvendo os professores de Educação Física dos dois turnos, apresentou-se como a mais promissora e aquela com maiores possibilidades de qualificação das ações coletivas e individuais da escola Vitória. Essa iniciativa se constituiu de encontros entre os professores para traçar metas conjuntas relacionadas com as principais ações da área a serem desenvolvidas durante o ano letivo de 2007.

[...] estamos fazendo uma coisa que a gente não fazia antes, sentando o grupo de professores, dos dois turnos, para estar definindo os conteúdos a

Movimento, Porto Alegre, v. 15, n. 04, p. 83-105, outubro/dezembro de 2009. 


\section{Astigos Orifinais Dionésio Heringer e Zenólia Figueiredo}

serem trabalhados. Este ano, pela primeira vez. Está sendo único. $\mathrm{O}$ mesmo conteúdo por bimestre na disciplina. Na escola. Nos dois turnos (CARMEMENTREVISTA, 2007).

Essa foi uma prática que, segundo a professora Carmem, não apresentou maiores resultados, pela dificuldade de se constituir com uma maior regularidade. De acordo com a professora, a dupla jornada de trabalho dos demais professores e suas atribuições de mãe não permitiram que os encontros acontecessem com a frequência desejada.

Demonstrando acreditar muito nessa modalidade de planejamento, Carmem aponta sua não efetivação, entre os professores de um modo geral, como um dos entraves para levar à frente aqueles projetos em que as ações devem ser desenvolvidas de forma coletiva. Reconhece as limitações legais para sua efetivação, destacando que o grande número de aulas dadas impede uma organização nesse sentido e aponta esse fato como uma necessidade urgente para a qualificação das práticas coletivas.

Uma experiência marcante nesse período de observações foi a participação do grupo de professores da escola no Congresso Espírito-Santense de Educação Física, organizado pelo Centro de Educação Física e Desporto da Universidade Federal do Espírito Santo. Importa registrar que esse evento contou com o apoio da SEME, quando financiou a inscrição de todos os professores de Educação Física da rede municipal que mostraram interesse em participar. Em se tratando da escola, foi fundamental a organização criada para que esses professores fossem liberados de parte de suas aulas e assim pudessem participar de quase todo o evento. Percebemos que, mesmo com os problemas gerados pela ausência desses profissionais em horários destinados a aulas, o CTA trabalhou no sentido de permitir e facilitar, na medida do possível, a participação dos professores da escola.

Vale registrar que a SEME delega à escola a prerrogativa de decidir pela liberação ou não de seus profissionais para a participação em eventos desse tipo. Situação que, segundo a professora Carmem, sempre se mostra favorável aos professores dessa escola.

Movimento, Porto Alegre, v. 15, n. 04, p. 83-105, outubro/dezembro de 2009 
Um ponto importante a ser acrescentado nessa experiência foi a disposição demonstrada por Carmem para participar do evento. Mesmo considerando sua disponibilidade profissional, estando livre por não atuar em outro horário, Carmem apresenta dificuldades de ordem pessoal para esse tipo de atividade, principalmente na rotina diária com sua filha.

Em relação à proposta de formação construída no ano de 2004, experiência que já citamos como de grande relevância na história de formação desse município, a participação da professora Carmem foi no sentido de envolver-se com todo o processo, desde aquele previsto no horário normal de trabalho, quanto a parte do projeto que previa encontros fora do horário de trabalho. Sua posição, na oportunidade, revelou um compromisso pessoal com aquele movimento, mesmo defendendo e cobrando a garantia de espaços/tempos de formação nos horários de trabalho.

Por fim, uma ocultação que merece análise é aquela que indica um descompasso entre os saberes constituídos no dia-a-dia de sua prática profissional e aqueles necessários a uma releitura de suas opções curriculares. Sobre isso, a própria Carmem relata:

[...] na medida do possível, a gente sempre está procurando essa autoformação, essa formação mesmo. Eu até ganhei o livro do Kunz, que eu não tinha. Vou até começar a ler. Até para poder conhecê-lo mais. É o segundo livro dele. E eu ainda não tinha. Mas eu vejo assim... Eu entendo que é de extrema importância, senão a gente fica assim... Sabe quando você... É como o computador... Eu não vou tocar no computador porque eu tenho medo. Se eu não toco, eu não aprendo. Então, eu tenho muita dificuldade com aquilo ali, mas, por quê? Porque eu também me limito a não trabalhar em cima e nem vivenciar. Então eu sei o básico do básico. Ou seja, eu não sei nada. Anecessidade é que, às vezes, me leva a buscar alguma coisa, aí, quando eu vou, eu vou e percebo que é muito fácil. Eu acho que não é por aí. Eu acho que a pessoa tem que estar sempre... Estar procurando, é claro, buscando (CARMEM - ENTREVISTA, 2007).

Movimento, Porto Alegre, v. 15, n. 04, p. 83-105, outubro/dezembro de 2009. 


\section{Artigos Orifinais Dionésio Heringer e Zenólia Figueiredo}

Esse relato da professora, oferecido para análise após sua participação no congresso de Educação Física, em que Carmem teve a oportunidade de manter um contato direto com o professor Kunz, evidencia uma vontade latente de realizar essa releitura curricular, o que a remete na direção de uma quase automática desvalorização dos saberes acumulados há tantos anos. Encontrar o equilíbrio necessário a uma análise coerente de sua prática inspirada nos indicativos de professor como intelectual crítico, articulador e transformador de sua prática, certamente não é uma tarefa fácil de realizar no isolamento profissional imposto por esse modelo hegemônico de organização escolar.

\section{ConsideraçõEs FINAIS}

Considerando a opção pelo estudo de caso, não pretendemos incorrer no erro de produzir generalizações com as considerações aqui apresentadas, nem tampouco impedir que aqueles que se aventurarem por esta leitura, valendo-se de sua experiência, façam suas associações e relações pessoais com outros contextos (ANDRE, 1995). Os resultados de nossa análise pretendem retratar algumas práticas construídas na particularidade de nosso local de pesquisa, pelos sujeitos que constituem esse universo, atravessados pelas influências produzidas pelas subjetividades de cada um deles.

Percebemos, claramente, a partir das práticas da professora de Educação Física colaboradora da pesquisa, o quanto a forma de organização do espaço escolar apresenta-se como determinante na limitação ou constituição das práticas de formação e no nível de envolvimento e cumplicidade dos sujeitos envolvidos. Nesse ponto do debate somos desafiados a entender os "consensos cognitivos" que desenham um quadro em que a necessidade de assegurar espaços de formação continuada antecede uma discussão sobre a qualidade desses espaços. A realidade brasileira, num contexto geral, ainda não tem garantido um movimento consistente no campo da formação continuada. Talvez por isso, os debates sobre o tema se caracterizam por argumentos que possam assegurar, ainda que de forma bastante incipiente, políticas que viabilizem esse movimento. Uma lógica clara que cria a "ilusão compartilhada" de primeiro garantir os espaços para, então, discutir sua qualificação.

Movimento, Porto Alegre, v. 15, n. 04, p. 83-105, outubro/dezembro de 2009 
Esse movimento cria uma ocultação importante sobre a responsabilidade com a condução desse processo. No contexto do debate acadêmico atual, não parece muito lógico imaginar uma ação de formação em que o sujeito a se formar atue como mero receptor daquilo que para ele for elaborado. Ao mesmo tempo, a ideia de assessoria em que o contratante, à luz de movimentos políticos instáveis, define a condução do processo de formação, tende a limitar as possibilidades de um envolvimento acadêmico consistente.

Inevitavelmente, o ponto central do debate desloca-se do questionamento de quem deve gerir esses movimentos, para o próprio sentido a eles atribuído. O nível de envolvimento dos professores passa a ser determinante nesse momento. Registra-se, então, a maior contradição desse campo em construção. Por um lado, se a formação continuada apresenta-se apenas como mais uma das "experiências sistêmicas", a rejeição dos professores salta aos olhos. Por outro, se esse mesmo sistema não elabora políticas de formação para que os professores possam dela participar, ele será duramente cobrado. 


\section{Artigos Originais Dionésio Heringer e Zenólia Figueiredo}

Practices of continuing formation in Physical
Education
ABSTRACT: It is a study in which its practices of
formation are analyzed at the moment when a Physical
Education teacher of a municipal school tries to make
effective the formation proposals foreseen in the policy
suggested by the Secretary of Education. It discusses
about the occultation that surround that area, generated
through consensus that create illusory projects. It
analyzes the school and the way how its organization
benefits and/or makes difficult the formation practices
built. It approachs the collaborator teacher to show
how that school space is organized and its presentation
as determinant in the limitation or constitution of such
formation practices.
Keywords: Education, continuing. Physical Education.
Professional practice.

Prácticas de la formación continua en Educacion Fisica

RESÚMEN: Esto a partir de un estudio en que las prácticas de la formación se analizan en el momento en que una profesora de Educación Física de una escuela municipal de la educación trata de llevar a cabo el proyecto de formación previsto en la formulación de políticas sugeridas por el Departamento de Educación. Discute occultations que rodean a este campo, generados por proyectos de construcción que crean poco realista. Examina la escuela y la forma en que su organización promueve y/o dificulta la formación práctica de la construcción. Estrecho de la maestra colaborador para revelar cómo se organiza la escuela que se presenta como crucial en la limitación o la constitución de estas prácticas de formación.

Palabras clave: Educación continua. Educacion Fisica. Práctica profesional.

\section{REFERÊNCIAS}

ANDRE, Marli Eliza Dalmazo Afonso de. Etnografia da prática escolar. Campinas, SP: Papirus, 1995

CORREIA, José Alberto. Os "lugares comuns" na formação de professores: consenso e controvérsias. Porto: ASA, 1999.

Movimento, Porto Alegre, v. 15, n. 04, p. 83-105, outubro/dezembro de 2009. 
ESTRELA, Maria Teresa. A formação continuada entre a teoria e a prática. In: FERREIRA, Naura Syria Carapeto. Formação continuada e gestão da educação. São Paulo: Cortez, 2006. p.43-64.

GIROUX, Henry A. Os professores como intelectuais: rumo a uma pedagogia crítica da aprendizagem. Porto Alegre: Artes Médicas, 1997.

MACEDO, Roberto Sidnei. A etnopesquisa crítica e multirreferencial nas ciências humanas e na educação. Salvador: EDUFBA, 2000.

MOLINA, Rosane Kreusburg; MOLINA NETO, Vicente. O pensamento dos professores de educação física sobre a formação permanente no contexto da escola cidadã: um estudo preliminar. Revista Brasileira de Ciência do Esporte, Campinas, v. 22, n. 3, p.73-85, maio, 2001.

MORGADO, José Carlos. Currículo e profissionalização docente. Porto: Porto Editora, 2005.

SACRISTÁN, José Gimeno. 0 currículo: uma reflexão sobre a prática. Porto Alegre: ARTMED, 2000.

SCHEIBE, Leda; BAZZO, Vera Lúcia. Políticas governamentais para a formação de professores na atualidade. Revista Brasileira de Ciência do Esporte, Campinas, v. 22, n. 3, p.9-21, maio, 2001. 